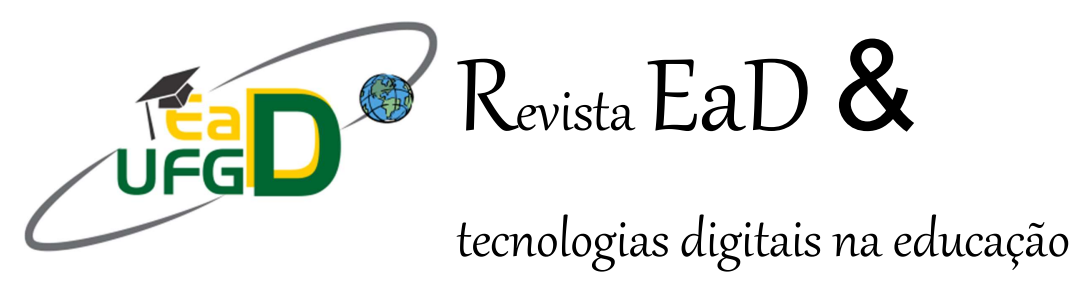

\title{
Surdos e seus pares linguísticos
}

\author{
Dariane Martins Barcelos Chita, UFGD \\ adbarcelos@gmail.com
}

\begin{abstract}
Resumo: A presente pesquisa é de natureza qualitativa etnográfica, tendo como objetivo apresentar um estudo de caso que busca analisar como ocorre a comunicação de um surdo oralizado que entra em contato com surdos usuários da língua de sinais. Utilizou como metodologia inicialmente uma revisão bibliográfica com autores que dialogam com o tema, como também uma entrevista informal semiestruturada. Como resultados, observa-se que somente a oralização não é suficiente para a educação de surdos, tendo em vista que a língua de sinais é a língua natural dos surdos, trazendo conforto comunicativo. No entanto podemos refletir que, apesar de haver pessoas se comunicando em Libras dentro da escola e surdos se reunindo cada vez mais no mesmo ambiente, estamos tratando de línguas diferentes dentro do mesmo espaço, logo, se tivermos uma sala bilíngue dentro da escola, ou uma escola bilíngue, estaremos garantindo o direito dos surdos de serem ensinados com a estrutura necessária para o aprendizado de sua língua, assim como a língua portuguesa já está garantida para os ouvintes.
\end{abstract}

Palavra-Chave: Educação, Surdos, Língua de Sinais.

\section{Introdução}

Os surdos e seus pares linguísticos foi um trabalho desenvolvido com o objetivo de comparar três escolas, onde um aluno surdo estudou, e descrever como era o seu desenvolvimento com e sem a presença da Língua Brasileira de Sinais (Libras) e de alunos surdos no mesmo ambiente escolar onde as trocas e experiências linguísticas acontecem naturalmente.

A pesquisa é de natureza qualitativa etnográfica que utilizou, como instrumento de coleta de dados, observação e entrevista semiestruturada, realizada por conversa informal com um aluno surdo, para que ele ficasse à vontade para expor seus sentimentos e emoções de experiências vividas em outros ambientes escolares e esclarecer, com naturalidade, sua opinião sobre a atual escola. O embasamento teórico foi feito por meio de estudo bibliográfico de autores conceituados que abordam o assunto. 
M. (como o identificamos o aluno surdo) está aprendendo a língua de sinais após entrar em contato com outros alunos surdos, num ambiente escolar que the proporcionou conhecer e identificar-se com uma nova forma de comunicação que the trouxe prazer e emoção. É através do convívio com outros surdos que o desenvolvimento acontece de forma satisfatória, logo precisam estar juntos, pois são minoria e compartilham muitas experiências dentro da escola e fora dela na construção de sua identidade.

Com a presença de alunos surdos na escola, surge a necessidade de professores, funcionários e comunidade em geral se mobilizarem de forma sistemática para a aprendizagem da Libras, com isso todos os alunos serão beneficiados e não apenas os surdos. Assim, além de observarmos a experiência anterior de $\mathbf{M}$. nas escolas, embora não seja principal objeto dessa pesquisa, também refletiremos sobre a importância da presença do intérprete de língua de sinais no processo de inclusão de alunos surdos no ensino regular.

Antes do tratamento dos dados, neste trabalho, serão destacados os três momentos vivenciados pela educação de surdos no Brasil, para esclarecer as etapas que não são mais efetivas, e o Bilinguismo, que tem sido uma proposta coerente com as necessidades educacionais dos surdos.

\section{Histórico da Educação dos surdos}

Diante de pesquisas bibliográficas temos que a educação de surdos passou por vários processos, este artigo destaca os três momentos vivenciados pela educação de surdos no Brasil para esclarecer as etapas que se mostraram pouco eficientes no ensino/aprendizagem dos surdos e o Bilinguismo, que tem sido uma proposta coerente com as necessidades educacionais dos alunos com surdez.

De acordo com Campello (2009, p.17), a primeira escola de surdos do Brasil foi o Imperial Instituto de Surdos-Mudos no ano de 1855, localizado no Rio de Janeiro, atualmente é o Instituto Nacional de Educação de Surdos (INES), lá ensinava-se disciplinas utilizando a língua francesa e a língua brasileira de sinais.

A Língua de Sinais era a base para a educação de nossas crianças e adultos surdos, era através dela que os conteúdos, conceitos e cultura eram ensinados diariamente, tínhamos uma educação de qualidade. Campello $(2009$, p.18) destaca que "...com o sucesso da apresentação dos alunos surdos ao Imperador Dom Pedro II, e da boa formação destes, os surdos tornaram-se repetidores (atualmente designados como monitores do professor), professores, escultores, pintores e outras profissões".

Mas, foi através de influências da educação na Europa que foi organizado o Congresso de Milão em 1880, onde ficou designado que o oralismo era a única forma dos alunos surdos terem educação. Conforme Campello (2009, p.17) relata : "Em 1880, um grupo de profissionais não surdos tomou a decisão, sem a participação dos professores e profissionais Surdos, de excluir a língua de sinais no ensino de Surdos", este foi um marco na educação de surdos pois neste congresso após a resolução de que todos os surdos precisam ter educação, houve a proibição da Libras com objetivo de educá-los apenas através da oralização, mas os surdos não participam, não tendo a oportunidade de se opor, logo a língua de sinais foi proibida dentro dos ambientes escolares e a oralização entrou em vigor.

No entanto, mais de um século se passou e outras formas de se ver a educação de surdos foram sendo propostas por estudiosos da área, com o intuito de se alcançar 
sucesso no ensino/aprendizagem desses alunos. Assim, podemos destacar as três filosofias marcantes na educação de surdos no Brasil:

Abordagem oralista: É o processo pelo qual se pretende capacitar o surdo na compreensão e na produção de linguagem oral e que parte do princípio de que o indivíduo surdo, mesmo não possuindo o nível de audição para receber os sons da fala, pode se constituir em interlocutor por meio da linguagem oral.

Abordagem da comunicação total: Nesta abordagem admite-se a utilização de uma língua gestual, porém vista somente como um passo de transição para a língua oral.

Abordagem bilíngue: A abordagem bilíngue surge como uma metodologia de ensino que tem sido utilizada por escolas que se propõem tornar acessíveis ao surdo duas línguas, no espaço escolar: a língua de sinais (L1) e a língua portuguesa (L2), em sua modalidade oral e/escrita. (LIMA apud RAFAELI e SILVEIRA, 2009, p. 17).

Conforme os estudos realizados por Fernandes (2006, p. 4), a Língua de Sinais é uma língua de um grupo minoritário, devido a estes fatores até o momento a Língua Portuguesa sempre será o foco, está é a situação em que se encontra o bilinguismo na atualidade. A mesma autora argumenta que a situação do bilinguismo nacional deverá oferecer as crianças surdas aprendizagem da língua de sinais como primeira língua até os três anos, seguida da aprendizagem da língua portuguesa, como segunda língua.

Ainda de acordo com Fernandes, o contexto de uma educação bilíngue para surdos deve atribuir conceitos diferentes dos utilizados na educação para ouvintes, pois não estamos falando de duas línguas auditivas como, por exemplo, a língua portuguesa e o inglês, mas estamos nos referindo a duas línguas diferentes dentro do mesmo país, com receptores diferentes, pois a língua portuguesa é oral-auditiva e a língua de sinais é visual-motora, por isso o ambiente direcionado para o ensino de ouvintes é diferente do ambiente e formas de aprendizagem dos alunos com surdez.

\section{Os Surdos e seus pares linguísticos}

O meio faz com que o aluno surdo consiga se desenvolver de forma satisfatória desde que eles estejam com seus pares, pois é na troca com pessoas fluentes que o aprendizado acontece mais rapidamente. A presença de intérprete não é suficiente para que o aluno seja incluído no ensino regular, tendo mais alunos surdos na escola auxilia no desenvolvimento, eliminando algumas barreiras e sendo beneficiado através da comunicação em Língua de Sinais, para que juntos possam compartilhar experiências através de sua língua natural.

Com a presença de vários alunos surdos na escola, surge a necessidade dos funcionários, professores e comunidade em geral de se mobilizarem de alguma forma para a aprendizagem da Libras, com isso os alunos serão beneficiados. Entende-se por Língua Brasileira de Sinais reconhecida pela Lei 10.436/02 (BRASIL, 2002), que apresenta gramática própria, sistema linguístico visual-motor e através dela expressa-se sentimentos e fatos dessa comunidade linguística. 
De acordo com Paterno (2007, p.7), “Com a implantação de novas políticas linguísticas na educação de surdos e em outras áreas que promovam a libras estão fazendo com que ela tenha um maior destaque e a ampliação da sua circulação".

\subsection{Resultados e Discussões}

Foi elaborado um questionário pertinente ao dia-a-dia do aluno M., estudante da escola municipal na cidade de Campo Grande/MS. A entrevista foi realizada através de uma conversa informal, para que ele sentisse à vontade para expor seus sentimentos e emoções através de suas experiências em outros ambientes escolares e esclarecer com naturalidade sua opinião sobre a atual escola. Logo após, será iniciado um esclarecimento das respostas dadas pelo aluno. Como tradutora/intérprete de Libras trabalhei escola que M. estuda, além da entrevista, algumas observações foram feitas para dar ênfase a pesquisa realizada.

O aluno M. estudava em outra escola que não era da rede municipal de Campo Grande, lá não havia nenhum aluno surdo e sua comunicação tinha que ser apenas através da oralização Quadros (2006, p.48), tem feito muitas pesquisas sobre o desenvolvimento da pessoa com surdez, em uma entrevista com uma aluna surda, destaca o seguinte depoimento da mesma: "Quando eu estudava em função do oralismo era difícil entender os professores. Apesar de me esforçar eu vivia perguntando. Até meus colegas reconheciam a dificuldade".

O sistema educacional imposto pela proposta oralista causou muito sofrimento aos alunos surdos porque eram forçados a fazer leitura labial dos professores, sendo que para os ouvintes é natural falar sem precisar estar olhando diretamente para quem está falando, mas no caso dos surdos o professor precisava estar olhando para o aluno, falar pausadamente, usar palavras simples e resumir o assunto, coisas que não aconteciam, sem contar que na maioria dos casos os surdos não aprenderam a ler os lábios.

No 70 ano M. mudou-se para uma escola da rede municipal de Campo Grande/MS, onde através de uma avaliação realizada por técnicos da Divisão de Educação Especial, da Secretaria Municipal de Educação (SEMED), ficou comprovada a necessidade de este aluno aprender a língua de sinais e ter o acompanhamento com o intérprete de Libras. A avaliação constatou que a oralização não estava sendo suficiente para o aprendizado do aluno, devido a sua surdez ser progressiva, assim, quanto antes ele estiver inserido na comunidade surda e usar a Língua de Sinais, melhor será. O suporte necessário para o ensino/aprendizagem dos alunos surdos está amparado pelo Decreto $5.626 / 05$, que assegura em seu artigo 23 que:

art 23. As instituições federais de ensino, de educação básica e superior, devem proporcionar aos alunos surdos os serviços de tradutor e intérprete de Libras - Língua Portuguesa em sala de aula e em outros espaços educacionais, bem como equipamentos e tecnologias que viabilizem o acesso à comunicação, à informação e à educação.

Através dessa entrevista foi constatado que os estudos estavam indo bem, mas o aluno sentia-se bastante isolado porque os colegas, funcionários e professores não tinham conhecimento da língua, logo, $\mathbf{M}$. se comunicava em língua de sinais somente com a intérprete. 
Verificamos que $\mathbf{M}$. gosta de usar língua de sinais, a mãe e a irmã não tem o conhecimento da língua e permanecem comunicando-se com ele através da oralização, mas aceitam que ele utilize onde for necessário sem nenhum constrangimento, mas o pai ainda não compreendeu a necessidade do filho usar a Libras, acreditando que apenas a oralidade é suficiente para a comunicação e aprendizagem. No entanto, os estudos têm mostrado que:

Para que relações sociais significativas possam se estabelecer, é preciso oferecer aos alunos todas as oportunidades de apropriação do acervo cultural produzido pela humanidade, para garantir-lhe uma formação integral e um exercício efetivo da cidadania. A educação de crianças surdas não pode reduzir-se ao treino da fala da língua oral. Mesmo que a Libras seja a expressão de um grupo minoritário, ela é parte integrante do acervo da humanidade. SÁ (2011, p.172).

Além do apoio do profissional intérprete na sala comum, o aluno foi encaminhado para o Atendimento Educacional Especializado aos Alunos com Surdez (AEE), M. participou algumas vezes com muita dificuldade, estava iniciando na língua de sinais e os outros alunos de sua idade, estavam bem avançados. $O$ aluno teve muitas faltas devido ao local do AEE ser oferecido numa escola distante de sua casa.

Pelo fato de não ter nenhum colega surdo na sua sala, nem na escola, este se sentia muito constrangido e em dúvida com relação à Língua de Sinais, utilizando mais da oralidade de forma simples do que a aprendizagem de uma nova língua. Os surdos precisam conviver com outros alunos surdos, principalmente com pessoas experientes usuárias da Libras, assim os alunos ouvintes que participam deste ambiente precisam aprender a Libras e se comunicar, para que os surdos sintam-se inseridos e juntos possam compartilhar experiências. De acordo com Sá (2011, p.174), "os alunos surdos devem se identificar com a própria cultura e com modelos de Identidade Surda. Os alunos ouvintes necessitarão aprender a pensar do ponto de vista surdo e assimilar algo da cultura".

A família transferiu M. para outra escola da rede municipal de ensino, onde está no momento, escola municipal de Campo Grande/ms, que atualmente é uma das escolas polo para atendimento aos alunos com surdez. Desde o início no ano 2011, a SEMED organizou cerca de 20 escolas polo para o atendimento dos alunos surdos com o auxílio do profissional intérprete, com o objetivo de reunir o maior número de alunos surdos por escola para haver a troca entre seus pares. Anteriormente, os alunos estavam espaIhados nas cerca de 90 escolas da REME e muitos ficavam sem a troca linguística, tão importante como já comentado neste artigo.

O aluno M. está feliz na nova escola, visto que há um total de onze alunos surdos e está sendo atendido por uma professora intérprete fluente em Libras. Ele sente grande satisfação de estar estudando nesta escola, pois há outro aluno surdo profundo e fluente em Libras estudando na mesma sala. A adaptação foi rápida e prazerosa, pois agora M. se identifica com a Língua de Sinais. De acordo com Sá (2011, p.170), "as pessoas surdas que não sabiam sinalizar anteriormente, aprendem a Libras rapidamente ao entrar em contato com outros surdos. Fato como este, demonstram como a Cultura Surda é específica". A comunicação através da Libras tem acontecido em alguns ambientes da escola, e vários alunos gostam de sinalizar, mesmo com muita dificuldade. Um destaque sobre a Língua de Sinais é descrito por Sá: 
Aprendizes ouvintes e surdos tem o direito de aprendê-la para que possam se comunicar com pessoas surdas em qualquer contexto. Os alunos surdos têm o direito prioritário de serem educados em Libras para que não sofram um processo de exclusão lingüística SÁ (2011, p.172).

A escola incentiva os professores, alunos e funcionários a aprenderem a Libras e através do Projeto Político Pedagógico da escola, estão sendo realizadas ações inclusivas em prol do ensino/aprendizagem dos alunos com necessidades educacionais especiais. Com isso, a intérprete do aluno M. foi solicitada em seu horário de planejamento para ministrar curso de libras aos funcionários administrativos da escola. Em relação ao decreto 5.626/05, sobre o uso e difusão da Libras, citamos:

Art. 14. As instituições federais de ensino devem garantir, obrigatoriamente, às pessoas surdas acesso à comunicação, à informação e à educação nos processos seletivos, nas atividades e nos conteúdos curriculares desenvolvidos em todos os níveis, etapas e modalidades de educação, desde a educação infantil até à superior.

No parágrafo 10 , caput $V$ do artigo 14 , referente aos cursos de formação para toda comunidade escolar, garante que se deve "apoiar, na comunidade escolar, o uso e a difusão de Libras entre professores, alunos, funcionários, direção da escola e familiares, inclusive por meio da oferta de cursos".

Os alunos ouvintes também estão se adaptando a este ambiente linguístico, muitos agem com muita naturalidade, respeito e admiração a esse movimento de inclusão dentro da escola. Apresentações em libras, com surdos e ouvintes tem acontecido dentro da escola, e fora dela os alunos surdos também tem feito apresentações de músicas e exposição de materiais confeccionados com eles e para eles, mobilização em favor da difusão da libras no Dia Nacional do Surdos foi realizado para esclarecimentos sobre este trabalho dentro da escola. Em contato com outros alunos surdos, tem proporcionado conforto a M., ótima comunicação e compreensão dos sinais, coisas que não acontecia antes, pois somente a presença da intérprete não era suficiente, atualmente conversa em sinais, passeia em vários lugares com amigos surdos e ouvintes que conheceu na escola e outros que consequentemente foi conhecendo de outros lugares.

Atualmente, o aluno $\mathbf{M}$. estuda no período vespertino no ensino regular e no contra turno estuda no Instituto Mirim (preparatório para o mercado de trabalho), lá também há intérprete e alunos surdos. Por esse motivo, não pode participar do Atendimento Educacional Especializado aos Alunos com Surdez que acontece no mesmo horário.

A abordagem oralista é a que M. estava habituado, não era momento confortável, porque dependia de muito esforço para participar da conversa e compreender os conteúdos, mas ao se deparar com sua língua natural, Língua de Sinais, ele sentiu prazer e alegria, mas isso não o impede de continuar utilizando a oralização quando necessário, pois ele tem vantagens em saber os dois. Mas a educação oralista foi fracassada e comprovada que são poucas as pessoas com surdez que conseguem se beneficiar através dela.

Embora tenha sido observado um avanço em vários aspectos no aluno M. por estar nessa atual escola, ainda há muitas dificuldades e barreiras para se alcançar o verdadeiro sucesso no ensino/aprendizagem de alunos surdos. A metodologia de ensino da 
escola comum inclusiva continua sendo direcionada para o ouvinte, assim, por mais que haja o profissional intérprete de Libras, este não suprirá todas as necessidades educacionais do aluno surdo.

A Secretaria Municipal de Educação de Campo Grande (SEMED) tem por meta futura alcançar todos os aspectos que se enquadram na proposta da educação bilíngue, visto que esta é a mais adequada para educação de surdos. Essa proposta defende que para os surdos a língua de instrução deve ser em sua língua natural, ou seja, em Língua de Sinais (L1) e a Língua Portuguesa deve ser ensinada como segunda língua (L2). Para tanto, é necessário a criação de classes bilíngues ou escolas de educação bilíngue, pois somente com essa estrutura será possível garantir que a Língua Brasileira de Sinais seja a língua de instrução, respeitando de forma total a língua e a cultura específica deste grupo minoritário.

A atual Política Nacional de Educação Especial na Perspectiva de Educação Inclusiva (2008), conforme destacado por Sá (2011, p.17), "fala-se muito em Escola para Todos, mas geralmente não se diz que ESCOLA PARA TODOS NÃO É SINÔNIMO DE MESMA ESCOLA". Por isso mudanças precisam ser tomadas para assegurar o ensino/ aprendizagem dos alunos com surdez, assim como dos alunos ouvintes está garantido.

\section{Considerações finais}

Por meio desta pesquisa, teve-se a oportunidade de se comprovar que somente a oralização não é suficiente para a educação de surdos, embora seja considerada como a mais próxima dos ouvintes, próxima da normalidade, no entanto, não leva em consideração a realização pessoal da pessoa surda. Mas, o contato com seus pares linguísticos permitiu ao aluno identificar-se e sentir-se mais confortável, ampliando seus conhecimentos dentro de um ambiente escolar acolhedor e mais próximo da realidade do surdo, ao invés de deixá-lo isolado no mundo dos ouvintes.

Também, apenas a presença do profissional intérprete não foi suficiente para a identificação do aluno com a Língua Brasileira de Sinais, foi necessário encontrar outros iguais. Além do encontro com seus pares, o ambiente escolar também favoreceu a quebra de barreiras, pois além dos alunos surdos e dos intérpretes, a utilização da Libras se estendeu também para todo o ambiente escolar, em prol desta comunicação, para que todos os alunos sintam-se inseridos.

No entanto, por mais que haja pessoas se comunicando em Libras dentro da escola e surdos se reunindo cada vez mais no mesmo ambiente, a proposta educacional para ouvintes é diferente da necessidade dos surdos, porque estamos tratando de línguas diferentes dentro do mesmo espaço, logo, se tivermos uma classe bilíngue dentro da escola, ou uma escola bilíngue, estaremos garantindo o direito dos surdos de serem ensinados com a estrutura necessária para o aprendizado de sua língua, assim como a língua portuguesa já está garantida para os ouvintes.

Pretende-se dar continuidade a esta pesquisa futuramente, com o objetivo de se comprovar que na escola bilíngue para surdos ou na classe bilíngue, o ensino/aprendizagem se torna mais eficiente para a educação destes alunos, lembrando que nessa proposta o aluno surdo será ensinado na sua língua natural, a Língua de Sinais, tendo a Língua Portuguesa como segunda língua. 


\section{Referências}

BRASIL. Lei no 10436/02. Brasília: MEC. Disponível em http://www.planalto. gov.br/ccivil/leis/2002/L10436.htm. Acesso em: 02.01.2012.

Decreto 5626/05. Brasília: MEC. Disponível em http://www.planalto.gov.br/ ccivil_023/_Ato2004-2006. Acesso em 09.01.2012.

. Política Nacional de Educação Especial na Perspectiva da Educação Inclusiva. 2008. Brasília: MEC. Disponível em http://portal.mec.gov.br/arquivos/pdf/politicaeducespecial.pdf. Acesso em 02.01.2012.

CAMPELLO, Ana Regina e Souza. Deficiência Auditiva e Libras. Indaial: Grupo Uniasselvi, 2009.

FERNANDES, Sueli. Práticas de Letramento na Educação Bilíngue para Surdos. SEED. Curitiba, 2006.

LIMA, Maria do Socorro Correia de. Algumas considerações sobre o ensino de português para surdos na escola Inclusiva. Revista Letra Magna. Ano 3, n.5, 2006.

PATERNO, Uéslei. A política lingüística da Rede Estadual de Ensino em Santa Catarina em relação à educação de surdos. Dissertação em lingüística, UFSC, 2007.

QUADROS, Ronice Müller de. Estudos Surdos I. Petrópolis, RJ: Editora Arara Azul, 2006.

RAFAELI, Kátia Solange Coelho; SILVEIRA, Maria Dalma Duarte. Língua Brasileira de Sinais - LIBRAS. UNIASSELVI - Indaial, 2009.

SÁ, Nídia Regina L. de. Surdos qual escola? Manaus: Editora Valer e Edua, 2011.

SILVA, Renata; URBANESKI, Vilmar. Metodologia do Trabalho Científico.Centro Universitário Leonardo da Vinci. - Indaial: Grupo Uniasselvi, 2009.

VYGOTSKY, L.S. Pensamento e Linguagem. São Paulo: Livraria Martins Fontes, 1993. 